\title{
ENTRE O ANTIGO E O MUNDO MODERNO: GUERRA E COMUNIDADE NA TIPOLOGIA DAS CIDADES DE MAX WEBER
}

\author{
Guilherme Moerbeck ${ }^{1}$
}

\begin{abstract}
Resumo
Economia e Sociedade, uma das obras mais influentes do início do século XX, com reflexos em diversos ramos das Ciências Humanas, é um texto de especial interesse aos pesquisadores da História Antiga, em especial na Tipologia das Cidades. Ainda que os objetivos maiores de Max Weber ao compor o seu texto estivessem vinculados, flagrantemente, à avaliação do mundo contemporâneo, a densidade do texto weberiano, fruto de uma erudição ímpar, revelou uma análise profunda e singular sobre a pólis, a cidade grega antiga. O objetivo desse artigo é analisar, sob a luz da crítica historiográfica e de uma análise cuidadosa da Tipologia, as escolhas interpretativas de Weber, em especial, no que se refere aos tipos ideais que construiu para compreender a cidade dos gregos antigos.
\end{abstract}

\section{Palavras-chave}

Max Weber; Economia e Sociedade; Tipologia das Cidades; Pólis; CidadeEstado; Tipos-ideais.

1 Professor Doutor - Universidade do Estado do Rio de Janeiro, Rio de Janeiro, Brasil. Email: gmoerbeck@yahoo.com.br 


\begin{abstract}
Economy and Society, one of the most influential oeuvres of the early twentieth century, with impact in several branches of the Human Sciences, has in one of its parts a text of particular interest to researchers of Ancient History, the Typology of Cities. Although Max Weber's significant aims in composing his text were, blatantly, to evaluate the contemporary world, the density of the Weberian text, the fruit of a unique erudition, revealed an in-depth and singular analysis of the ancient Greek city. The purpose of this article is to analyze Weber's interpretive choices, in the light of historiographical criticism and a careful analysis of the Typology, in particular as regards the ideal types which he made to understand the city of the ancient Greeks.
\end{abstract}

\title{
Keywords
}

Max Weber; Economy and Society; Typology of Cities; Polis; City-State; Ideal types. 


\section{Introdução}

Max Weber, nascido no mesmo ano em que Fustel de Coulanges publicava A Cidade Antiga, 1864, teve uma vida cheia de atribulações de ordem política. Censurou a entrada da Alemanha na Primeira Guerra e, depois, direcionou suas críticas ao Kaiser, Guilherme II, cuja condução da guerra o desagradava. Não deixou de criticar os grupos revolucionários de esquerda que foram sufocados na República de Weimar, nem tampouco poupou de críticas a ascensão da extrema direita na mesma época. $\mathrm{O}$ isolamento político de Jacob Burckhardt não servia a Weber, muito embora este mesmo pensasse ser a inserção na política e na ciência percursos que requeriam diferentes compromissos éticos. As suas profundas incursões por tantas áreas lhe renderam muitas obras, até hoje tidas como marcos na produção científica, mas também períodos de convalescença oriundos de fortes crises psíquicas, relacionadas à morte do pai em 1897 e às decepções políticas na Alemanha da sua época (Pollak, 1996: 59-60; Pollak, 1996b: 878; Moerbeck, 2016: 89-90).

O objetivo central desse artigo é o de analisar da forma mais sistemática possível as considerações de Weber sobre a cidade ocidental antiga, com especial atenção ao caso grego. No entanto, uma pequena digressão inicial pode ser útil para trazer ao horizonte do leitor alguns elementos de advertência. Deve ser lembrado que a tipologia das cidades é uma abordagem profundamente sociológica e de viés fortemente comparativo entre muitas sociedades antigas, que vão desde a Grécia, Roma, China, Egito, Índia, Japão, Mesopotâmia, além de outros períodos como a Idade Média. Tendo como ponto de referência a forma de dominação legítima e racional, o Estado moderno, Weber se propõe a pensar as formas de dominação não legítimas, como a cidade antiga (Finley, 2013: 17-9). Atentese que, na acepção weberiana, o Estado moderno era "um sistema de instituições e de relações impessoais que envolvia [...] uma entidade territorial com um poder centralizado que monopolizava o uso do poder coercitivo" (Goldstone e Haldon, 2009: 5).

Nesse mesmo sentido há um conjunto muito relevante de debates acerca das inspirações de Weber nos debates relativos à natureza da economia na Antiguidade, que remonta ao final do século XIX e tem a ver com discussões na área da Economia que mobilizavam as escolas alemã, austríaca e inglesa, em especial o economista Karl Bürcher. As problemáticas relativas à aproximação de Weber do primitivismo e debates com outras correntes da economia da época devem interessar ao leitor, pois formam a base de algumas das mais importantes reflexões weberianas. Embora não desenvolvidas de forma didática aqui, foram abordadas muitas vezes por historiadores e sociólogos que as explicam em maiores 
detalhes (cf. Carvalho, 2011: 45-7; 51-2; Carvalho, 2018: 447; 463-4; Cardoso, 2005: 133-48; Iggers, 1983: 8-10; Vlassopoulos, 2007: 36-7; Palmeira, 2009: 95-6; Morley, 2004: 33-7; Scheidel; Morris; Saller, 2008: 1-2; Nippel, 1991: 20-1; Cohn, 2002: 8-10).

\section{A cidade antiga ocidental: o longo percurso da tipologia das cidades.}

\section{Conceitos e categorias de cidade}

Como caracterizar conceitualmente uma cidade? Para Weber, é o que se constitui como um "povoado" em "um assentamento fechado" e não como um conjunto de moradias isoladas (Weber, 1999: 408). Se a quantificação de habitantes, bem como a disposição espacial das edificações são importantes, não é menos relevante o aspecto jurídico como elemento definidor da existência de uma cidade. A formação de uma cidade depende: a) da existência de um centro, que pode se confundir com uma sede senhorial e/ou um oikos². Weber está pensando nas possibilidades da formação da cidade em termos de necessidades econômicas, no comércio e nas suas formas de relações políticas; b) da realização regular de trocas de bens. Nesse sentido, deveria existir um mercado que atendesse às necessidades dos moradores.

Toda cidade no sentido aqui adotado da palavra é 'localidade de mercado', isto é, tem um mercado local como centro econômico do povoado [no qual] também a população não urbana satisfaz suas necessidades de produtos industriais ou artigos mercantis [...] a cidade (no sentido aqui adotado da palavra) é um assentamento com mercado permanente (Weber, 1999: 409-410).

O elemento político-administrativo também opera na caracterização do conceito de cidade. Ao proclamar-se como unidade autônoma, uma comunidade (die Gemeinde) ${ }^{3}$ com instituições políticas e administrativas especiais, ter-se-ia, outrossim, a formação de uma cidade. Não menos importante é a ideia de que a cidade na antiguidade se constituiria como uma guarnição militar, como uma fortaleza, expressa material e simbolicamente por meio de uma muralha.

2 O oikos é considerado por Weber um grande consumidor do mercado local, por meio do qual poderia satisfazer as suas necessidades de serviços ou produtos (Weber, 1999: 409-10).

${ }^{3}$ Os tradutores para o português optaram pela palavra comuna, enquanto em inglês puseram a palavra "commune" entre aspas. Eu adoto a palavra comunidade em meu texto por ser, hoje, um termo antropológico mais corrente e que parece fazer mais jus ao sentido empregado por Weber no decorrer de seu texto. 
Em busca de uma tipificação da cidade, Weber estabeleceu pelo menos duas variáveis que serviam de elementos preditivos por meio das quais ele construiu um tipo-ideal: a primeira é a forma de consumo realizado pela cidade; a segunda, é a relação entre cidade e campo ${ }^{4}$. O tipo de cidade-fortaleza que Weber imagina organiza-se a partir da conjugação de elementos militares, políticos e jurídicos (estamentais) que envolvem espaços de reunião da assembleia militar de cidadãos. Tudo isto deveria ser somado à existência do mercado local. Essa composição é denominada "dualismo plástico", o que faz o autor alemão ressaltar que, no caso ático, a ágora era o espaço no qual se resolviam as questões econômicas, políticas e, até mesmo religiosas, antes de haver uma pnyx (Weber, 1978: 1224; Weber, 1999: 419-20).

Em síntese, essa comunidade, tipicamente ocidental, ou ao menos muito mais frequente, dependia da formação de

[...]povoados com caráter artesanal-comercial pelo menos relativamente desenvolvidos, que apresentassem as seguintes características: 1) uma fortificação, 2) um mercado, 3) um tribunal próprio e pelo menos parcialmente um direito próprio, 4) caráter de associação e, ligadas a este, 5) autonomia e autocefalia pelo menos parciais e, portanto, uma administração realizada por autoridades, em cuja nomeação participassem de alguma forma os cidadãos como tais (Weber, 1999: 419-20).

Por vezes, é difícil lidar com a argumentação de Weber, pois, a despeito de sua busca classificatória acerca do que seria uma cidade e comunidade, em alguns momentos fica muito pouco explícito se havia variações em seus

${ }^{4}$ Weber desenvolveu a noção de tipo ideal, um recurso metodológico, para responder aos problemas que a enorme variedade de fenômenos observáveis na vida social requeria. Consiste em tomar certos traços da realidade, exagerando-os unilateralmente, de tal forma que pudessem ser percebidos na maneira mais pura possível. O tipo-ideal parte do mundo empírico e suas infinitas possibilidades para criar um instrumento analítico que não pode ser equiparado ao mundo vivido de maneira direta, pois apenas um fragmento dessa realidade poderá constituir-se, de cada vez, objeto da apreensão científica. Assim, tratava-se de selecionar uma determinada variável cultural, por exemplo: como determinados preceitos religiosos foram importantes no desenvolvimento de um sentido ético-religioso de trabalho. Tais preceitos, ao orientar a vida por meio de um ethos ascético, sustentáculo de uma moral que despreza o corpo e suas sensações como busca do aperfeiçoamento espiritual, impulsionaram as ações e a formação de um estrato capitalista e de ideias capitalistas. Estas relacionavam-se às condutas racionais que levaram ao sucesso no trabalho e que se expressam simbolicamente como sinal da "salvação" em determinadas sociedades cuja base era protestante. A questão fundamental para Weber, neste caso, é que o indivíduo que incorporou a ética do espírito do capitalismo não é produto, mas produtor o próprio regime em questão (Cohn, 2002: 8; Weber, 1999b: 105-110, Weber, 2001: 35-42; Mathias, 2006: 4-8; Cardoso, 2012: 8-10; Ringer, 2004: 116; Fontana, 1998: 169-185; Carvalho, 2011: $61)$. 
conceitos. O que significaria empiricamente "autocefalia e autonomia ao menos parciais"? O que fazia a autonomia ser parcial, qual o critério? Quando diz que a Idade Média está fora desse modelo, refere-se a toda a Idade Média 5 ? E quanto às comunidades urbanas modernas, quais atenderiam a esse critério de elegibilidade à categoria de comuna/comunidade?

\section{Dois tipos-ideais: a cidade consumidora e a Ackerbürgerstädt}

O mais conhecido dos tipos-ideais de Weber, muito por conta da apropriação feita por Moses Finley, gira em torno da ideia de cidade consumidora (Konsumentenstadt) ${ }^{6}$. A cidade consumidora é um construto que depende de uma especificação: quem consome o quê? Prevalece a ideia de que a cidade é composta de consumidores rentistas, isto é, proprietários de terras que viviam das rendas provenientes delas para adquirir outros produtos no mercado local. Note-se que Weber é cuidadoso ao alertar aos mais empiristas que "parece óbvio que quase todas as cidades empíricas constituem tipos mistos e, por isso, somente podem ser classificadas segundo os seus componentes econômicos predominantes" (Weber, 1999: 412).

Quando menciona o caso da Antiguidade em termos genéricos, Weber quer se referir ao caso grego e romano, fora isto, faz menções explícitas ao oriente próximo ou extremo. No mundo ocidental, que também inclui a Europa Medieval, as cidades abrigavam "propriedades feudais e sedes de linhagens com senhorios territoriais fora da cidade e, muitas vezes, também com grandes propriedades fundiárias dentro da cidade [...]" (Weber, 1999: 426).

Talvez seja importante esclarecer que Weber utiliza termos que causam certo desconforto à leitura contemporânea. Muitas vezes, menciona a existência de um capitalismo antigo, embora não queira se aproximar de um viés analítico modernista. Ao contrário, Weber reconhece a natureza específica da economia antiga, de forma análoga ao que faz com a ideia de Estado moderno quando comparadas às formas de dominação ilegítimas

5 Weber retoma essa ideia mais à frente comparando, grosso modo, algumas características da cidade antiga ocidental com as da região do sul da França e do Norte da Península Itálica para a baixa Idade Média.

${ }^{6}$ Há outros tipos-ideais, como a cidade mercadora (Handelstadt) e a cidade produtora que, por serem mais encontradas em sua forma ideal no período medieval, são importantes para nós, apenas na medida em que ajudam na compreensão dos modelos de cidades mais típicas para a antiguidade ocidental (Weber, 1999, p. 412-25).

Heródoto, Unifesp, Guarulhos, v.4, n.1 - 2019.1. p.139-167

DOI: 10.34024/herodoto.2019.v4.10108 
(pré-modernas). Ao falar de capitalismo, relaciona-o a um sentido geral, isto é, em como "uma economia de produção a satisfação das necessidades de um grupo humano se faz por intermédio da empresa, pouco importando a natureza das necessidades a satisfazer (Weber apud Carvalho, 2018: 468)". Weber utilizou, embora com menos frequência no Economia e Sociedade, a ideia de feudalismo citadino. A ideia weberiana de que a cidade grega arcaica era uma "corporação de guerreiros ligados a um sistema de caráter igualitário" já aparecia em texto anterior, no Agraverhältnisse. A estrutura escravista teria sido um dos elementos que fez com que a cidade feudal perdesse força ainda na antiguidade. $\mathrm{O}$ caso espartano seria o mais característico de um processo de democratização, que acabou com a forma de feudalismo e de domínio senhorial na antiguidade (Colognesi, 2001: 21-2). Novamente, uma ideia que pode parecer estranha ao olhar contemporâneo, mas é exatamente a noção que Weber queria expressar, ao ver como os esparciatas mantinham a forma de divisão da terra entre si, concomitante à diminuição dos poderes vinculados a uma estrutura mais aristocrática.

Outro tipo-ideal, oriundo da relação entre cidade e agricultura, opera na conformação de uma cidade de agricultores/ "agrarian cities" /Ackerbürgerstädt (Weber, 1999: 412; Weber, 1978: 1217). Trata-se de um tipo de cidade que o próprio Weber enfatiza ser "a grande maioria das cidades típicas (póleis) da Antiguidade" (Weber, 1999: 413). Em linhas gerais, Weber constrói um tipo-ideal no qual os cidadãos são produtores agrícolas residentes na cidade, mas que vão trabalhar diariamente em campo próximo (Hansen, 2006: 86).

\section{Três elementos da cidade antiga ocidental}

Outro empenho de Weber no sentido de compreender a cidade foi o de tipificá-la como uma cidade ocidental, havendo uma diferenciação ainda a fazer, pois existiam os modelos antigo e medieval. Há, pelo menos, três características que definem o fenômeno da cidade ocidental antiga, ela era: estamental, militar e religiosa.

O caráter estamental é central e refere-se, no caso antigo, ao pertencimento ou não a um clã ${ }^{7}$, além de considerar o fato da existência da posse de terras. Segundo o nosso autor, o mundo mediterrânico era onde essas diferenças estamentais se apresentavam de forma mais acentuada. Muito embora,

\footnotetext{
${ }^{7}$ Mais à frente, Weber trata de forma análoga o termo clã à fratria encontrada em Atenas (Cf. Weber, 1999: 430).
}

Heródoto, Unifesp, Guarulhos, v.4, n.1 - 2019.1. p.139-167

DOI: 10.34024/herodoto.2019.v4.10108 
como um "mercado de oportunidades", a cidade mediterrânica oferecia oportunidades para os ganhos materiais, desde as construções públicas em Atenas, nas quais escravos conviviam com trabalhadores livres, até ao que se refere às possibilidades em torno do pecullium 8 em Roma. Assim, o fato de existir um sistema estamental, que garantia privilégios jurídicos a um determinado grupo social, não impedia que, na esfera econômica, houvesse a coexistência de cidadãos de status superior com habitantes que, embora inferiores sob um determinado prisma, acumulassem mais riquezas do que os próprios cidadãos. "A cidade ocidental, tanto na Antiguidade quanto na Rússia, era um lugar de ascensão da servidão à liberdade, por meio da atividade aquisitiva no regime da economia monetária" (Weber, 1999: 426-7).

Para Weber, muito pouco importa precisar as diferenças na realidade grega vista em sua diacronia e, nem mesmo, entre as civilizações grega e romana que, neste momento de seu texto, aparecem quase que completamente fundidas. Em geral, Weber utiliza a mesma terminologia para a cidade da Idade Média quanto para a Antiguidade. Um exemplo é o termo burguesia, que é análogo a artesãos/mercadores/comerciantes. No entanto, ao observar a relação entre cidade e campo, preserva as distinções entre a cidade antiga e a medieval. É esta a variável que separa esses mundos. $\mathrm{Na}$ análise weberiana, o mundo medieval e sua cidade produtora conjugavam o gérmen do que veio a ser o capitalismo9.

A cidade antiga ocidental de Weber se constituiu a partir de um conjunto de instituições políticas e jurídicas que garantiam a separação estamental do cidadão urbano dos outros grupos que habitavam a pólis. Isolando-o analiticamente sob esse prisma, o cidadão era o membro superlativo da pólis. A cidade desenvolvida tanto na Antiguidade quanto na Idade Média era uma "associação constituída como irmandade", mas em cujo núcleo residia a forma de associação religiosa, "um culto exclusivo da associação de cidadãos, um deus ou santo da cidade que os protegesse como tais" (Weber, 1999: 429).

Embora não houvesse, como acontecia na Índia e na China, o impedimento do casamento de cidadãos urbanos por conta de tabus, Weber pondera que

8 Como é bastante sabido, processo por meio do qual um escravo pode reunir recursos para comprar a sua manumissão.

${ }_{9}^{9}$ No mundo medieval ocorreu "uma apropriação monopolista das oportunidades de ganho pelo trabalhador [mestre] individual" baseada no trabalho livre e não no escravo. Este era amplamente utilizado do modelo da cidade antiga ocidental. Note-se ainda, que "a organização livre do artesanato com regulamentação de corporações é classicamente ilustrada pela Idade Média europeia e só em tal caso tornou-se a forma predominante" (Weber, 1964: 261; 233).

Heródoto, Unifesp, Guarulhos, v.4, n.1 - 2019.1. p.139-167

DOI: 10.34024/herodoto.2019.v4.10108 
os atos sagrados dos clãs eram vedados àqueles que não eram seus membros natos, como nos rituais de comensalidade (Weber, 1999: 430). A origem da própria pólis é marcada por essa organização clânica, pondera Weber. Argumentação esta que nos leva a traçar uma vinculação sensivelmente próxima à desenvolvida por Fustel de Coulanges, embora Weber não o cite em nenhuma passagem do longo texto da tipologia das cidades (Fustel, 2009; Hartog, 2001: 7-46; Herán, 1987: 67-97). Essa aproximação também tem a ver com o fato de essas comunidades familiares (clãs) serem baseadas em uma ascendência comum "que constituía, por sua vez, uma associação cultual rigorosamente exclusiva em relação a estranhos" (Weber, 1999: 430). Ademais, tais clãs ou mesmo as suas confederações possuíam, sobretudo, um caráter militar, que foi sofrendo transformações em suas formas organizativas com o passar do tempo ${ }^{10}$. Essas linhagens que compõem as cidades e se unem aqui e ali numa simbiose entre a religião e guerra foram perdendo o seu amálgama desde a origem da pólis até o Período Clássico.

É bem verdade que Weber, em outra parte da Tipologia, foi bem mais cuidadoso na análise desse processo sob o ponto de vista diacrônico, o que, no entanto, não o impedia de fazer toda sorte de analogias. Para além da questão de uso conceitual, o problema é que Weber compara, sem maiores reservas, ritos da comensalidade nos genoi gregos aos eventos descritos em uma carta de Paulo aos Gálatas, na qual tece um relato dos ritos de confraternização. Note-se que Weber está trabalhando com, pelo menos, quinhentos anos de distância no tempo. Ainda que seja quase impossível ao historiador da antiguidade não aceitar certo anacronismo conceitual no processo analítico, especialmente no percurso entre passado e presente, é preciso enfatizar, como o fez Nicole Loraux, o fato de que, por um momento, é preciso "suspender as próprias categorias culturais" para depois se pôr num pêndulo temporal. Assim, o anacronismo pode ser um instrumento interessante à reflexão histórica, desde que esteja sob controle e que o historiador permaneça consciente de suas propriedades (Weber, 1999: 430; Loraux, 1992: 57-70)11.

Em seu próprio devir temporal, a pólis se impôs como uma comunidade estamental de cidadãos com especial atenção à formação militar. Em alguns momentos, Weber caminha, novamente, muito próximo à interpretação fusteliana, embora seja do alemão a maior ênfase nos efeitos dessa comunidade militar. Ao se olhar as cidades medievais, o que se vê é

10 Na minha leitura, Weber parece sugerir as reformas de Clístenes no bojo dessas transformações.

${ }^{11}$ Seria injusto não agradecer à Prof ${ }^{a}$. Marta Mega de Andrade por me apresentar este texto de Nicole Loraux.

Heródoto, Unifesp, Guarulhos, v.4, n.1 - 2019.1. p.139-167

DOI: 10.34024/herodoto.2019.v4.10108 
uma "confederação de cidadãos individuais", de pais de família. Na Antiguidade, havia uma noção de "comuna", com autonomia política, em contraposição a de Estado, somente com o Estado helenístico a comuna perderia a sua autonomia (Weber, 1999: 431). Essa questão tencionava a avaliação que Weber fazia da política moderna, para o qual a política era o conjunto de esforços visando participar do poder ou influenciar a divisão do poder, seja entre estados, ou no interior deles. Assim, para Weber, e depois para Finley, o locus no qual opera a política é o Estado, pois toda pessoa que participa da política aspira ao poder independentemente dos seus fins $^{12}$ (Weber, 2002: 60-1, Finley, 1985: 68-73; Mac Gaw, 2003: 238-49).

Dentre outras coisas, Weber assinala que as religiões da Antiguidade conheceram apenas o vestígio do culto aos antepassados como uma limitação tabu, as compara às realidades indianas e asiáticas em geral, e isso se devia a questões religiosas internas ou, com pouca certeza, em relação à vida marítima e à expansão colonial que ajudavam a romper vínculos clânicos mais exclusivos.

E mesmo que na Antiguidade fossem por toda parte restabelecidos artificialmente, segundo a tradição, mediante a organização das novas comunidades em associações de gentes e fratrias, a unidade fundamental não era mais a associação gentilícia, mas a associação militar da pólis (Weber, 1999: 431).

Tanto para o caso ateniense quanto para o caso romano, a fundação da cidade formava uma comunidade religiosa que poderia envolver diferentes grupos étnicos. O que parece fundamental é que "[...] pertencer a uma dessas associações permanecia a característica do cidadão pleno..." (Weber, 1999: 433). O que se quer frisar é ideia de que no mundo medieval o cidadão adquire existência individual em sua comunidade e em sua posição jurídica, enquanto na antiguidade, as várias formas de associação político-jurídica, e mesmo religiosas, embotam, ou ao menos tornam bem mais complexa, a visualização dessas redes de relação citadinas.

Embora Weber utilize termos como: nativos e membros de tribos estranhas (cf. Weber, 1999: 432-3), deve-se mencionar que há uma interessante reflexão acerca das relações comunitárias étnicas no Economia e Sociedade. Ressalto aqui a ideia de Weber de que uma comunidade, [importante notar o uso desse termo ao longo de toda a Tipologia], pode fixar-se em certas convenções, atuando como geradora de costumes. Por consequência, seleciona tipos antropológicos na base da criação de sujeitos sociais. A

\footnotetext{
12 Não se deve confundir a ação política com a noção ou conceito de poder. Para Weber, o poder é algo mais geral que está ligado à possibilidade de uma pessoa ou várias, numa ação social, impor a vontade própria em uma ordem jurídica, ainda que não somente na estatal (Weber, 1999: 154-186).
}

Heródoto, Unifesp, Guarulhos, v.4, n.1 - 2019.1. p.139-167

DOI: 10.34024/herodoto.2019.v4.10108 
diferença em relação ao exterior, (às outras comunidades), assim como a homogeneização interna pode ocorrer a partir de elementos quaisquer, por mais superficiais que sejam. Acerca desse problema, Fredrik Barth veio falar de fronteiras étnicas, o que muito guarda relação com as formas de distinção a que Weber faz menção. O que chamamos hoje de processo de alteridade, de fabricação do humano, do outro por meio da seleção de um elemento cultural variável no tempo. Dessa maneira, encerra Weber, mostrando que qualquer forma comum ou contrária do hábito ou costume pode gerar uma crença subjetiva de que existe uma afinidade ou heterogeneidade de origem. Notadamente, a crença na afinidade de origem pode ter consequências importantes para a formação de comunidades políticas (Weber, 1999b: 267-77; Barth, 1998: 185-227).

\section{A cidade grega na diacronia weberiana}

\section{A cidade das linhagens}

Apesar da ancoragem temporal irregular nas reflexões de Weber, a segunda parte de sua Tipologia, em especial a da cidade grega, assume uma orientação mais precisa do ponto de vista cronológico. O início de sua narrativa refere-se à pólis em seus primórdios, portanto, algo entre os séculos VIII e VII a.C. Este é um período aparentemente híbrido, pois já não é o da realeza micênica e de seu aparato patrimonial-burocrático que remete às formas de dominação orientais, mas de um governo baseado em linhagens aristocráticas, de guerreiros que se unem em um exército cavalheiresco nos quais os duelos ainda decidem as batalhas. Note-se que Weber continua utilizando conceitos que transitam entre a realidade grega, romana e mesmo medieval. Na relação entre Agamemnon e Aquiles, fala na doação de um feudo (Weber, 1999: 457), depois, ao tratar da imagem de anciães que aparecem no escudo de Aquiles; menciona ainda, os clãs de "honoratiores que se destacam pela propriedade e pelos méritos militares" (Weber, 1999: 458). Acompanhar a reflexão weberiana inclui o esforço de interpretar tais conceitos segundo a semântica que concerne ao próprio autor e não apenas por meio da crítica contemporânea dos mesmos.

A cidade aristocrática típica da antiguidade, segundo Weber, era aquela que reunia alguns elementos: trata-se de uma cidade litorânea, fora do território da pólis -, não é possível inferir se Weber se refere ao núcleo urbano ou ao território da cidade como um todo ${ }^{13}$. Havia aldeias (chomai) e união de tribos (ethne). O processo de sinecismo, base da formação da

${ }^{13}$ Se se tratar do núcleo urbano, é símile ao que, analiticamente, Robin Osborne uma vez chamou de town para a cidade grega antiga (Osborne, 1987: 9).

Heródoto, Unifesp, Guarulhos, v.4, n.1 - 2019.1. p.139-167

DOI: 10.34024/herodoto.2019.v4.10108 
pólis, pressupõe a convivência dessas linhagens, eventualmente com um rei, e, retomando o argumento expresso algumas páginas acima, utilizando-se de um "castelo fortificado" (Weber, 1999: 459). Os mundos grego e romano aparecem, às vezes, como uma tinta borrada no papel de Weber, nas poucas vezes que se refere a outros autores, como a E. Gothein, menciona que "[...] as [linhagens] da Antiguidade continuavam, em parte, residindo em seus castelos rurais ou pelo menos possuíam - e isto constituía regra - casas de campo, além de uma sede urbana" (Weber, 1999: 459).

O conjunto das relações sociais que dão vida à forma espaço-territorial expressa acima é composto fundamentalmente por uma economia de subsistência e de um "comércio passivo"14 aliados a um elemento militar com preceitos éticos estruturantes, talvez um habitus, em torno da valorização do jovem e da cultura agonística. A valorização dos jovens na cidade, especialmente em torno da impetuosidade para a guerra, aparece de maneira controversa entre os antigos. O olhar de Eurípides na sua Suplicantes mostra um pouco dessa tensão. Por um lado, a cidade que anula a força dos jovens torna-se fraca e alimenta a ascensão de tiranos, por outro, o furor belicoso em demasia, a philotimia da juventude pode colocar o futuro de uma pólis em risco (Bourdieu, 2009: 87; Moerbeck, 2017: 263-75). Em síntese, para Weber, a pólis se estruturava em torno de um caráter gentilício (genoi), nos quais o poder carismático era estruturante das relações sociais.

O processo de consolidação do poder da pólis, ainda nesse período, teve a ver com o fato de as comunidades de culto inerentes à cada linhagem terem perdido poder para a cidade. Era por meio do ritual de comensalidade, característica da cidade ocidental, que uma nova comunidade era fundada. “Na Antiguidade, essa confraternização significava o nascimento de uma nova comunidade local de comensais e cultual [...] opunha-se à confraternização o culto de cada linhagem, que excluía por toda a parte os não-membros [...]" (Weber, 1999: 460)15. A pólis se torna a senhora do patrimônio dos deuses. Por outro lado, no mundo oriental, como a China e a Índia, a divisão em castas impedia esse tipo de fraternidade que, no caso da Idade Média, será assumida pela comunidade de cristãos, por meio da eucaristia (Nippel, 1991: 26-8).

14 Weber insiste que, para aquela época, o comércio ativo ainda estava nas mãos dos fenícios (Weber, 1999: 458).

${ }^{15}$ Não é incomum que Weber teça comparações com o Período Clássico - como no caso do enfraquecimento dos genoi, a concentração das necrópoles próximas à cidade e a função das phylai na política e administração da cidade Cf. (Weber, 1999: 460-1).

Heródoto, Unifesp, Guarulhos, v.4, n.1 - 2019.1. p.139-167

DOI: 10.34024/herodoto.2019.v4.10108 
A relações econômicas parecem ser um tanto quanto ambíguas nas formulações de Weber. O argumento em relação à Ática é o de que os astoi, (residentes nas cidades, mas deve ser entendido como cidadãos para o sentido que Weber deu ao termo), eram os que acumulavam as melhores terras e as exploravam por meio da servidão por dívidas, em detrimentos dos camponeses (diacrios) que, por sua vez, ocupavam as encostas, muito menos produtivas. Parece claro que Weber se refere aqui ao período préSólon, ao informar que esses agroikoi e perioikoi estavam alijados da participação política, que ficava nas mãos da camada guerreira urbana ${ }^{16}$.

Do ponto de vista econômico, a propriedade da nobreza era, como é natural, sobretudo de caráter senhorial-territorial. Os serviços dos escravos, servos e clientes [...] constituíam a base da satisfação das necessidades [...] a fonte do poder econômico da típica nobreza urbana era a participação direta ou indireta no comércio ou na navegação, que ainda na época tardia era considerada compatível com a posição social e somente em Roma foi proibida aos senadores (Weber, 1999: 462).

Weber analisa em um mesmo conjunto a situação do patriciado da Babilônia, da Hélade e da Idade Média e não há nenhum indício mais específico a qual período exatamente se refira. No entanto, o julgamento do nosso autor quanto à participação da "nobreza típica" no comércio não se sustenta à análise mais detida dos argumentos utilizados nos escritos dessa mesma elite, ao menos no caso da grega ${ }^{17}$. Nobreza típica, sem dúvida, é um conceito frouxo, ainda mais utilizado para tantas realidades socioeconômicas distintas. O máximo que podemos deduzir, à guisa de síntese ao leitor, é que se trata de uma nobreza fundiária que possuía residência na cidade. Para o caso grego, ambiguamente no discurso de Weber, a nobreza parece se envolver com o comércio e com a navegação sem que isso lhe causasse estigma social algum.

Um erro muito comum em historiadores do XIX, era considerar a visão negativa que a elite ateniense atribuía ao trabalho artesanal e/ou comercial como se fosse um desiderato universal, ou seja, inerente à toda a população ateniense, quiçá mesmo a todos os helenos. Essa visão foi expressa em muitos autores do período clássico, como Xenofonte, Aristóteles e Aristófanes, sendo, posteriormente, problematizada e lida à contrapelo pela historiografia contemporânea (Pires, 2014: 815). De toda maneira, subsiste a dúvida se Weber ignora ou se discorda desse ponto de vista da

16 Para uma reavaliação do papel dos grandes legisladores e a questão do poder carismático, cf. (Arnason, 2013: 30-33)

17 Ellen Meiksins-Wood explica muito bem o processo de apropriação da opinião da elite ateniense pela historiografia contemporânea como se tratasse da opinião dos atenienses como um todo, (cf. Meiksins-Wood, 1989: 05-42).

Heródoto, Unifesp, Guarulhos, v.4, n.1 - 2019.1. p.139-167

DOI: 10.34024/herodoto.2019.v4.10108 
elite grega. Afirmar que o comércio poderia ser amplamente feito pela aristocracia, sem que isso não lhes incutisse mancha social, seria uma perspectiva divergente das leituras da mesma época.

Navega-se nos argumentos de Weber com dificuldades. Trata-se de uma incômoda percepção pensar que, para o caso de muitas cidades, o tipo da cidade de agricultores (Ackerbürger) expressasse uma realidade demasiado modesta para que pudesse existir um comércio e navegação como a "fonte do poder econômico da típica nobreza urbana". Por outro lado, Weber acentua o caráter consumidor de cidades que possuíam forte comércio, como Atenas e Corinto. Ora, se estas são hipotéticas cidades consumidoras, dadas as suas características populacionais e territoriais, como pensá-las a partir da perspectiva de uma elite que se dedicava fortemente ao comércio, embora, contraditoriamente, desprezasse esse mesmo comércio no nível ideológico no âmbito discursivo? Há algo que não se encaixa nessa sistemática. Ou Weber está certo na afirmativa acima, e o comércio é tão importante que as grandes cidades gregas não se encaixariam facilmente em tipo-ideal algum, ou o nosso autor não enxerga de maneira clara as distinções de valor que a aristocracia ateniense fazia quanto ao trabalho na terra, no artesanato e no comércio. Ao termo, Weber parece não resolver em que medida a relevância do comércio afetaria a lógica de uma cidade centrada no consumo, em seu próprio mercado interno e na redistribuição monetária por meio das rendas oriundas do campo e do próprio Estado18 (Vernant e Vidal-Naquet, 1989; Moerbeck, 2017; Wood, 1989: 05-42. Paiaro, 2018: 93-134).

\section{A cidade plebeia}

O objetivo central de nosso autor nesse trecho da Tipologia é o de refletir sobre o processo através do qual a cidade de linhagens começa a erodir. Nesse percurso, Weber não se furta a múltiplas comparações da cidade antiga com o mundo medieval, especialmente no tocante ao surgimento do popolo (empresários e artesãos) nas cidades do norte da Península Itálica, o que envolvia o financiamento da ação das massas contra a nobreza de linhagem. As referidas ações seriam símiles às lutas institucionais da plebe, no âmbito da política da república romana, especialmente no que se refere aos interesses plebeus defendidos pelo tribuno da plebe ${ }^{19}$.

${ }^{18}$ Deve ser lembrado que Weber só possuía os textos dessa elite (ateniense ou não) para a sua reflexão, assim, a sua análise acaba por ser guiada pelas ideias dos autores antigos. ${ }^{19}$ Uma das referências de Weber nesse trecho é Eduard Meyer (Weber, 1999: 474).

Heródoto, Unifesp, Guarulhos, v.4, n.1 - 2019.1. p.139-167

DOI: 10.34024/herodoto.2019.v4.10108 
O que Weber quer precisar é que a lutas contra as linhagens são lutas estamentais. Assim, seu interesse é declaradamente ver as similitudes no modus operandi das divisões legais, a despeito das diferenças políticas, sociais e econômicas dos mundos grego, romano e medieval, porque: “[...] não se dispõe de uma variedade infinita de formas técnico-administrativas para regular compromissos estamentais dentro de uma cidade ..." (Weber, 1999: 475).

Essas mudanças sociais não significaram a igualdade irrestrita imediata, mas, na verdade, um processo em etapas. Na primeira, no caso da democracia ateniense, o voto na Eclésia, a assembleia popular, foi concedido a todos os cidadãos. Depois disso, o pertencimento à nobreza de sangue deixa de ser critério sine qua non para a ocupação de altos cargos públicos e nos conselhos. Por fim, mesmo pequenos comerciantes e artesãos não proprietários de terra conseguiram ascender a todos os cargos públicos da cidade. Dessa forma, o censo econômico, que ainda criava barreiras à participação política, desaparece na Atenas do século IV a.C.

Embora, novamente, lembre em alguns aspectos a análise fusteliana, Weber revela interesse em uma avaliação mais detida na maneira como as mudanças de caráter administrativo-jurídico também se expressavam na dimensão espacial da pólis. Para isso, utiliza o caso da democracia ateniense, que criou um distrito local, denominado demos, uma "subseção de todo o território e fundamento de todos os direitos e deveres na pólis (Weber, 1999: 477) ${ }^{20}$. A pólis deixa de ser "uma confraria de associações militares e gentilícias [e passa a ser] uma corporação territorial de caráter institucional" (Weber, 1999: 477). Dessa forma, "em lugar da judicatura carismática irracional apareceu a lei. Paralelamente à eliminação da dominação das linhagens, iniciou-se a legislação" (Weber, 1999: 477). Com a diminuição do poder do Areópago, provavelmente na década de 480 a.C., teria ocorrido um tipo de fratura simbólica do poder aristocrático, empreendida durante o arcontado de Efialtes que, após comandar a realização das reformas, foi assassinado.

A virada à democracia mantém íntima relação com a mudança de um governo baseado nas ligações consanguíneas e de poder carismático para aquele em que se governa mediante o uso da lei, da eleição de magistrados

${ }^{20}$ Noutro trecho, Weber menciona que a cidade democrática estava dividida segundo tribos e demoi e possuíam caráter eminentemente rural. A divisão da cidade em bairros é algo que a cidade antiga compartilha com a da Idade Média e mesmo com a oriental. Havia, de toda forma, um domínio da cidade, de tal forma que "formalmente as aldeias se tornassem [...] subdepartamentos da cidade" (Weber, 1999: 498).

Heródoto, Unifesp, Guarulhos, v.4, n.1 - 2019.1. p.139-167

DOI: 10.34024/herodoto.2019.v4.10108 
e por meio de sorteios ${ }^{21}$. De forma concomitante à criação de uma visão da elite ateniense sobre o trabalho, há, outrossim, o surgimento de um topos discursivo que caracterizava uma ideologia democrática. Assim, não apenas na Política de Aristóteles, mas, bem antes, nas Histórias de Heródoto e nas Suplicantes de Eurípides aparecem claramente os elementos que dão forma àquilo que os atenienses entendiam como a base do regime democrático (Moerbeck, 2017: 151-223).

Weber ressalta que a democracia trouxe consigo um novo tipo de dirigente, geralmente um estratego, um dos dez generais de Atenas que, embora fosse um servidor público, não o era na acepção moderna da palavra. A remuneração para o cargo era muito pequena, não havia uma carreira pública como, em certo sentido, houve em Roma algum tempo mais tarde, até porque, em muitos casos, sequer se poderia ser reconduzido ao cargo. $\mathrm{O}$ estratego, que poderia ser reeleito e requeria atividade integral, era ocupado por pessoas abastadas.

O processo em questão começa a aparecer sutilmente no discurso de Weber como uma espécie de elemento de deformação do governo da lei, assim, "o verdadeiro dirigente da política, criado pela democracia plenamente realizada - o demagogo - costumava ser formalmente em Atenas, no tempo de Péricles, o supremo funcionário militar" (Weber, 1999: 478). Neste momento, foi estabelecido com o povo um tipo de relação que transcendia a lei e o cargo, enquanto cidadãos importantes atuavam por meio da "influência pessoal e na confiança", novamente, estamos muito próximos do que Weber define como o poder carismático, que estava na base do funcionamento do sistema ateniense (Weber, 1999: 478).

Nesse sentido, Weber se apropria de uma visão bastante negativa dos "desvios" da democracia ateniense produzida no século IV, muito influenciada por autores como Aristóteles e Aristófanes. O domínio carismático, que se estabeleceu concomitantemente às diversas bases legais22, ocorria quando havia a deturpação dos usos da vida política ordinária. O carisma tem a ver com o "poder sobrenatural", fora do comum, de uma dada pessoa, em arregimentar seguidores e partidários. Na política existem alguns tipos: o demagogo, o ditador, o herói militar ou

${ }^{21}$ Note-se que Weber não equipara esses novos funcionários do governo democrático à burocracia estatal moderna devido às remunerações, muitas vezes consideradas irregulares, bem como devido ao fato de não poderem, em muitos casos, exercer o mesmo cargo após o término do período para o qual fora escolhido.

22 Enquanto no caso de Atenas se estabelece na democracia, no caso da cidade-estado de Jerusalém aparecia na figura religiosa, do profeta (Weber, 1999b: 136).

Heródoto, Unifesp, Guarulhos, v.4, n.1 - 2019.1. p.139-167

DOI: 10.34024/herodoto.2019.v4.10108 
revolucionário ${ }^{23}$. A entrega do poder ao líder carismático pressupõe a crença de que ele é predestinado a uma missão, pois o fundamento do poder carismático é emocional e não racional. A confiança nele depositada, muitas das vezes, é fanática, cega (Dabdab-Trabulsi, 2001: 50-66).

Seria o demagogo guiado por uma ética da convicção 24 ? O carisma aparece como rompedor do sistema tradicional ou legal, quebra as instituições e/ou as põe em dúvida. A legitimidade do líder carismático não é tirada das leis, nem da tradição, mas sim, dele mesmo, das suas certezas, da sua própria fé acerca do que deve ser feito, muito embora, o seu reconhecimento e legitimidade possam ser conferidas por meio da eleição em um sistema democrático. Por fim, deve-se ressaltar que o próprio Weber considerava que muitas relações de dominação estão fundadas num conjunto de crenças, no mundo empírico, em bases mistas (legal, tradicional e carismática). Há, inclusive, a possibilidade da conversão da dominação carismática em tradicional quando se torna cotidiana (Weber, 1999: 134-141; Weber, 2002: 73-90).

\section{Pensando a democracia grega}

A cidade na Antiguidade tentava combater as diferenciações econômicas. Igualmente, havia muitos cidadãos plenos que, embora arruinados, aguardavam as benesses do Estado em diferentes formas de subsídios, especialmente a de camponeses pobres devedores, geralmente sem-terra. Weber compara essa situação com o "the poor White trash", a camada que representava a escória branca no sul dos EUA escravista.

A política econômica da pólis democrática, se nos permitirmos esse termo ao mundo antigo, era concentrada nas formas de intervenção do governo nos interesses mercantis e dos consumidores (os proprietários residentes na cidade) e nas maneiras pelas quais se distribuía rendas, como as provenientes das minas do Láurio. Considerando esse sistema, houve um conjunto de programas, tais como: a proibição da venda de cereais em Atenas, bem como a imposição de tributos aos aliados da Liga de Delos.

A escravidão era um dos alicerces da economia, não apenas da agricultura, mas também do setor artesanal no qual trabalhavam livres e não-livres.

\footnotetext{
${ }^{23}$ No mundo contemporâneo, Weber pensa como demagogos os políticos e membros de partidos políticos, bem como jornalistas e publicitários envolvidos no jogo propriamente político (Weber, 2002: 81-91).

24 Recaímos no problema das justificativa dos fins pelos meios, de uma convicção pura que tem consequências sociais negativas (Weber, 2002: 115-120).
}

Heródoto, Unifesp, Guarulhos, v.4, n.1 - 2019.1. p.139-167

DOI: 10.34024/herodoto.2019.v4.10108 
Havia, no entanto, limitações à composição de associações e/ou corporações profissionais, como era comum em alguns exemplos da Idade Média. O que Weber quer chamar a atenção é que "a democracia na Antiguidade era uma "corporação burguesa" dos cidadãos livres, caráter que determinava todo o seu comportamento político [...]" (Weber, 1999: 499). Mas, note-se que a noção de cidade de consumidores tem a ver não com a criação de uma demanda de produtos à moda moderna.

A pequena burguesia urbana [...] estava interessada em rendas diretas ou indiretas procedentes do bolso das comunas dependentes, isto é, construções públicas, subsídios para assistir às apresentações teatrais e participar na assembleia de jurados (a heliaia), distribuição de cereais e outras coisas, tudo financiado pelo Estado com impostos dos súditos (Weber, 1999: 500).

$\mathrm{Na}$ antiguidade ateniense, antigas linhagens tradicionais: "phyles e fratrias", são divididas em "demoi e tribus 25 ", o que Weber chama de corporações políticas. "Isto quer dizer duas coisas: primeiro, rompe-se a influência das linhagens, pois a propriedade destas era, correspondendo à sua origem em empréstimos e insolvência, em grande parte propriedade dispersa [...]" (Weber, 1999: 500). O que se quer assinalar é que, com o advento dos demoi, tudo tinha que ser registrado e um imposto pago, o que diminuía o poder da antiga propriedade baseada num modus operandi de poder tradicional. Os demoi permitiram a ocupação dos postos políticos com os seus membros, e essa é a grande questão para Weber, pois marca a ascensão política dos camponeses. "E isto quer dizer que na Idade Média, desde o princípio, os artesãos eram os portadores da democracia e na antiguidade, na época de Clístenes, os camponeses" (Weber, 1999: 501).

Além disso, por que a guerra era fundamental? O demos estava muito interessado na guerra porque representava a possibilidade de adquirir bens, semelhante ao que aconteceu com o trabalho de marinheiro, o qual Weber chama, entre aspas, de "desemprego / benefício do desemprego". Assim, "estes cidadãos desclassificados não tinham compromissos econômicos e nada a perder". (Weber 1999: 502, Weber, 1974: 1350).

Todo esse arrazoado ajuda a entender porque a antiguidade não foi o trampolim para o capitalismo moderno, considerando-se o fato de que o "desenvolvimento democrático da Antiguidade não chegou a praticar uma autêntica política industrial de produtores, como elemento decisivo [...] a política urbana da Antiguidade persegue, em primeiro lugar, os interesses dos consumidores urbanos" (Weber, 1999: 502). Na Antiguidade ocidental, não se deixava apenas nas mãos dos comerciantes urbanos o abastecimento

25 Aqui e em outras passagens, preferimos manter as transliterações originais de Weber tiradas da tradução portuguesa mencionadas nas referências. 
de cereais da cidade. Tratava-se de uma política de Estado aliada aos interesses de grandes proprietários e de pilhagens que operava a partir de um fator litorâneo (geográfico) determinante na visão de Weber ${ }^{26}$.

A reforma hoplítica, em sua luta contra as linhagens, está diretamente ligada à transição à democracia, já que esse processo teria sido o que eliminou politicamente a nobreza. A eliminação da nobreza variou muito, desde o caso mais radical de Esparta, em que Weber parece olhar muito desconfiado para a visão da terra como "propriedade comum" (Weber, 1999: 505), até à própria manutenção dessa mesma nobreza em Roma. Em Atenas o caminho foi a da "incorporação da nobreza aos demoi" no sentido de um Estado timocrático, já no tempo de Clístenes (Weber, 1999: 504).

\begin{abstract}
A cidade específica da Antiguidade, suas camadas dominantes, seu capitalismo, os interesses de sua democracia, todos esses fatores estão primariamente orientados para aspectos políticos militares, e isto tanto quanto mais se destaca o caráter específico da Antiguidade (Weber, 1999: 504) [...] Um demos desse tipo [que primava pela guerra como forma aquisitiva, especialmente de escravos] jamais podia estar primariamente no sentido de atividades econômicas pacíficas e de uma gestão economicamente racional (Weber, 1999: 511).
\end{abstract}

A pólis democrática era uma corporação de guerreiros, de cidadãos como homens políticos. Após a derrocada das linhagens, os hoplitas eram a classe dos cidadãos plenos, esse tipo de posição decaiu com o aparecimento de mercenários e da frota em cidades litorâneas (Weber, 1999: 505-510). A partir desse ponto, surge outro topos discursivo que se repete em Burckhardt, Fustel e Weber, a saber: a inexistência da noção de liberdade entre os atenienses. Aristóteles era leitura obrigatória e cuidadosa de todos, que considerava a democracia de Atenas demasiadamente radical e mesmo uma distorção do sentido de politeia (Ober, 1998: 290-5).

Pode-se mesmo especular que, no âmbito da apropriação e ressignificação das ideias políticas, a pressuposição de Aristóteles sobre a necessidade da propriedade para a plena participação adequa-se perfeitamente a uma forma de visão oligárquica na invenção da república contemporânea que justificaria os ativos na política. Note-se, outrossim, a relação causal estabelecida por Weber entre a utilização da mão de obra escrava em larga escala, as guerras promovidas para a obtenção de cativos com a impossibilidade de se estabelecer um tipo de economia pacífica, racional, além do progresso técnico que fizesse emergir o capitalismo moderno na Antiguidade (Weber, 1999: 510; Wagner, 2013: 61; Carvalho, 2018: 470).

${ }^{26}$ Não é sem relevância que Weber faça menção a Pausânias (cf. Weber, 1999: 510-11).

Heródoto, Unifesp, Guarulhos, v.4, n.1 - 2019.1. p.139-167

DOI: 10.34024/herodoto.2019.v4.10108 
A despeito de Péricles ter afirmado que os atenienses poderiam viver como queriam, o fato para Weber era que,

[...] a corporação dos cidadãos interferia, à discrição, na vida de cada indivíduo. Uma propriedade mal administrada, especialmente a dissipação do lote de herdado por um guerreiro [...], o adultério, um filho mal-educado, o mau tratamento dos pais, a impiedade, a hybris - todo comportamento que punha em perigo a ordem e disciplina militar e civil ou podia provocar a ira dos deuses, em desvantagem da pólis - eram punidos [...] não se pode falar de uma liberdade pessoal na condução da vida, e a medida, que de fato existia, diminuía a força combativa da milícia dos cidadãos, como aconteceu em Atenas (Weber, 1999: 510).

Weber, e tantos outros intelectuais da sua geração tiveram que se digladiar intelectualmente com muitas questões. De toda forma, o ambiente das gerações do historicismo do século XIX deixou marcas em sua obra. Aliás, era o que ocorria em relação ao conceito das liberdades liberais, que só poderiam ser alcançadas por meio das estruturas tradicionais do Estado moderno. A burocracia de um estado, como o da monarquia prussiana, poderia ser o melhor garantidor da defesa das liberdades individuais e da segurança jurídica em relação às democracias que tendiam a se inclinar ante as pressões da opinião pública (Iggers, 1983:10-7).

A forma por meio da qual a pólis se arrogava direitos de subtrair o patrimônio dos cidadãos é uma das bases de se pensar a pólis como forma de dominação ilegítima. O Estado Moderno se torna mandatário (por meio de um pacto) e tem como prerrogativa garantir os patrimônios dos signatários desse acordo simbólico e legal. Enquanto isso, na pólis, a manutenção dos patrimônios era muito instável, já que, por meio das liturgias, vários cidadãos se viam obrigados a se empenhar economicamente pelo bem comum. Ademais, como Weber poderia admitir uma justiça em que os processos civis eram impetrados e julgados por cidadãos sem nenhum conhecimento jurídico específico e formal? Tudo isso parecia, ao olhar weberiano, em constante instabilidade política.

\section{Considerações finais}

Muito da proposição de que a Grécia foi uma espécie de adolescência da civilização europeia, já que a infância teria sido o mundo oriental, já estava presente de forma enfática em F. Hegel (Bernal, 1987: 294-6). A busca de Weber em compreender a formação da cidade antiga ocidental tem muito a ver com as chaves que procurava para o entendimento de seu próprio mundo, para compreender a cultura de finais do século XIX e o advento do Estado moderno. 
As interpretações de Moses Finley acerca do modelo ideal para a cidade antiga, como o da cidade consumidora, de tão influente, acabou por jogar uma cortina de fumaça sobre a maneira pela qual o próprio Weber pensava a cidade antiga. Ledo engano pensar que a leitura de Finley poderia dar conta do alto grau de complexidade weberiana. Os erros e/ou distorções de Finley, ao misturar os dois tipos de cidade consumidora e de Ackerbürgerstält já foram apontados em outros trabalhos por Mogens Hansen e Kostas Vlassopoulos. Quiçá, a indisposição de Finley em trabalhar com os dados da cultura material para a compreensão da cidade antiga possa ter parte nesse processo de limitação interpretativa. No entanto, estamos no campo das especulações, que dizem mais sobre a maneira como o campo lida com as apropriações de ideias do que com a medida em que Weber estava correto ou não em suas interpretações (Hansen, 2006: 85-98; Vlassopoulos, 2007: 123-141).

O núcleo que extraímos da análise weberiana quanto à cidade antiga ocidental (grega e romana) está apoiado na tríade: estamental, militar e religiosa. E operava na coexistência de sofisticadas distinções de status, legais e de classe27. Toda cidade para Weber cumpre certas características sem as quais não faria sentido sequer denominá-la cidade. O cerne da questão está nas formas pelas quais em seu centro físico reside um mercado para que as trocas de bens se realizam. Como funciona esse mercado em um mundo agrário? Dois tipos ideais dão forma ao funcionamento dessas entidades espaciais, jurídicas, econômicas, políticas e militares conhecidas como cidade consumidora e cidade de agricultores.

A essa altura, Weber não precisa mais dizer que Esparta é consumidora ou mesmo Atenas, ou que ainda outras tantas fossem cidades de agricultores. Ainda que Hansen demonstre que Weber havia sido mais sofisticado em sua análise do que o próprio Finley, o problema está em tentar comparar o tipo-ideal às cidades realmente existentes. Hansen acaba fazendo isso, ao mencionar que o problema do modelo weberiano (da cidade consumidora) é que ele se aplica apenas a algumas póleis entre mais de mil (Hansen, 2006: 86-7; 94-8). O modelo criado por Weber não foi construído para ser comparado a realidades empíricas in totum, mas para traçar um percurso de compreensão dos significados das transformações empíricas ocorridas

${ }^{27}$ Considerando-se a acepção de Weber quanto à classe, que tem a ver com uma posição em relação ao mercado. A propriedade não é fundamento para a divisão da sociedade em classes, opera, no entanto, como fonte de privilégios e discriminação no ambiente do mercado. Evidentemente, Weber está mais preocupado com esses debates no mundo contemporâneo, para o qual pensa que as classes não determinam necessariamente a formação de grupos sociais distintos, porque não tem relação necessária com a divisão social do trabalho.

Heródoto, Unifesp, Guarulhos, v.4, n.1 - 2019.1. p.139-167

DOI: 10.34024/herodoto.2019.v4.10108 
no tempo, e que poderiam levar ao melhor entendimento da formação do Estado moderno e do capitalismo. Isso não isenta o discurso de Weber de falhas e imprecisões quanto ao mundo antigo ou exime os seus tipos ideias de serem, ao termo, pouco plausíveis à análise da realidade antiga.

Weber está em constante distanciamento e aproximação do mundo empírico. Quando se empenha em tentar entender o processo pelo qual a pólis transitou de uma configuração de linhagens até a democracia, lá estava a ponte para entender o distanciamento do seu tipo-ideal. Atenas, a cidade que mais nos legou fontes escritas, se tornou o núcleo desse percurso diacrônico de Weber, como se poderia esperar de um texto escrito da década de 1910. O empenho de nosso autor é tentar analisar como, do ponto de vista histórico, as cidades reais se aproximam ou não de seu modelo ideal.

Dessa forma, de uma cidade aristocrática, cujo poder estava baseado em uma forma híbrida de dominação tradicional/carismática, apoiada em uma elite guerreira, até à cidade democrática de Atenas, percebe-se uma transição em que os elementos territorial-legal-institucional se impuseram à tríade do Período Arcaico gentilícia-militar-carismática. Parece que a cidade de Atenas é a consumidora para Weber. É aquela em que o poder militar de uma elite que habitava a cidade explorava as rendas provenientes do campo. Trata-se principalmente de proprietários de terras que fomentam a guerra como possibilidade de aquisição e de tributação de cidades súditas.

Atenas era uma economia irracional e jamais poderia produzir o capitalismo moderno, pois estava assentada em uma lógica de instabilidade referente às constantes guerras e quanto à propriedade de seus cidadãos. A própria concepção de Weber sobre a democracia contemporânea era uma das fontes de seu estranhamento ao olhar para a democracia das massas em Atenas, porque "o regime democrático [moderno] pode eventualmente facultar o revezamento graças às eleições ou de outras formas de consulta à maioria, mas de fato é sempre uma minoria que decide e orienta segundo suas diretrizes a política geral do agrupamento" (Freund, 2000: 162). Assim, a igualdade de condições jurídicas tem mais a ver com a concepção weberiana relativa à dominação racional-legal do que a aceitação de que a ampla maioria devesse participar efetivamente do processo político.

O comércio pulsante de Atenas era um problema do qual Weber tinha consciência, mas, ainda assim, acreditava ser limitado o suficiente para avançar noutra interpretação que romperia com a sua posição primitivista. Ao termo, o que caracterizava a cidade democrática era a tríade baseada 
na propriedade da terra, na comunidade militar governada, eventualmente, por um líder demagogo e nas formas de tributação que transferiam rendas a um sistema que, como toda cidade, pressupunha um mercado.

Os debates ensejados por esse artigo levantam questões de duas ordens. A primeira delas diz respeito à condição da historiografia contemporânea, em especial no que concerne às reflexões sobre temas muito caros, tais como: o evolucionismo, as bases econômicas do mundo antigo e as distorções causadas pela pressuposição da noção de Estado em suas análises. Nesse mesmo sentido, há perigos em pensar o Estado como um fator de coesão das sociedades, e, até mesmo, acerca da própria condição da História Antiga como uma forma histórica específica e legítima para todas as sociedades indistintamente.

Há muitos desdobramentos desta problemática que, ainda hoje, possui significativo alcance no campo da Teoria da História, bem como nas outras formas de história que incluem a escolar e o universo da história pública. Desde a formação de um campo de estudos clássicos até o atenocentrismo oitocentista ainda expresso em muitos livros didáticos brasileiros, o fato é que a História Antiga como um campo de estudos, bem como as divisões, muitas vezes arbitrárias, entre ocidente e oriente, é ainda hoje objeto de disputas que transcendem os debates no campo científico em direção aos jogos políticos que subjazem as escolhas e pressupostos tomados nas posições de poder na própria academia (Guarinello, 2003: 41-61; Vlassopoulos, 2007: 13-46; Francisco e Morales, 2016: 67-79; Shanks, 1996: 80-5; Moerbeck, 2018: 140-6; Wagner, 2013: 47-67; Andrade, 2016: 95-105; Bernal, 1987: 294-6; Carvalho, 2018: 473-4, Gallego, 2018: 86; Lisarrague, 2002: 101).

As formas de apropriação e ressignificação de conceitos políticos são muito importantes em nosso próprio tempo. Como bem ressaltou Peter Wagner, a ideia de república ganhou espaço em detrimento das práticas da democracia (Wagner, 2013: 51). Já se considerava, no final do XIX, o fato de a noção de república não implicar a participação maciça de pessoas. A noção de república ganha ares de politeia, quando passa a domesticar os "feitios disruptivos da democracia", especialmente a participação popular. As ideias que falavam em uma revolução democrática no XIX eram claramente contra o modelo da democracia ateniense. A ideia de liberdade se tornou central desde as discussões do iluminismo tardio, mas ganhando várias nuances: liberdade da injustiça; liberdade como realização pessoal; liberdade tida como expressão pessoal; liberdade no comércio ou como autodeterminação coletiva. Esta última, mais próxima da experiência grega, acabava entrando em conflito com as primeiras acima. "A resposta 
que se cristalizou após 1800 foi o que agora conhecemos como o conceito liberal de liberdade, uma liberdade que não emergia da coletividade, mas que precisava ser protegida contra ela" (Wagner, 2013: 52). Note-se que o reconhecimento dos direitos individuais é perfeitamente compatível, na experiência moderna, com um governo não democrático.

Não seria possível em um espaço tão limitado retomar todas essas questões, muito embora deva-se lembrar as grandes mudanças de perspectiva pelas quais a história da cidade antiga vem passando. Se era fundamental para Weber, assim como também foi para Marx, compreender em que medida havia diferentes mundos que se podiam dividir em realidades orientais e ocidentais, agora, ao contrário, essas divisões parecem demasiado arbitrárias para se pensar um mundo grego muito mais integrado às realidades que ultrapassam a cidade como unidade de análise. Trata-se de uma mutação espaço-material que, desde o final da década de 1970 e, ainda mais a partir de meados da década de 1980, empenha-se em avaliar mais a rede dos gregos e não-gregos no Mediterrâneo do que a das póleis vistas em sua unidade e isolamento (Marx, 1985; Hodern e Purcell, 2000; Brock \& Hodkinson, 2001; Morris 2003; Vlassopoulos 2007; Malkin, 2012; Guarinello, 2013, Polignac, 1995, Snodgrass, 1981).

\section{Referências Bibliográficas}

ANDRADE, Marta Mega de. Pólis: comunidade, política e a vida em comum numa leitura da Política de Aristóteles. In: Revista Clássica, v. 28, $\mathrm{n}^{\circ}$ 1, p. 95-124, 2016.

ARNASON, Johann P. Exploring the Greek needle's eye: civilizational and political transformations. In: ARNASON, Johann P.; RAAFLAUB, Kurt, A; WAGNER, Peter. (Ed.) The Greek pólis and the invention of democracy: a politico-cultural transformation and its interpretations. Malden: WileyBlackwell, 2013, p. 30-32.

BARTH, Fredrik. Grupos étnicos e suas fronteiras. In: POUTIGNAT, Philippe e STREIFF-FENART, Jocelyne. Teorias da etnicidade seguido de Grupos étnicos e suas fronteiras de Fredrik Barth. Trad. Elcio Fernandes. São Paulo: Editora da UNESP, 1998, p. 185-227.

BERNAL, Martin. Black Athena: the afroasiatic roots of classical civilizations. New jersey: Rutgers University Press, 1987, vol I. 
BROCK, R.; HODKINSON, S. Alternative to Athens: varieties of political organization and community in Ancient Greece. Oxford: Oxford University Press, 2001.

BOURDIEU, Pierre. O senso prático. Petrópolis: Vozes, 2009.

CARDOSO, Ciro Flamarion. História e Conhecimento: uma abordagem epistemológica. In: ; VAINFAS, Ronaldo. (Orgs.). Novos Domínios da História. Rio de Janeiro: Campus, 2012, p. 01-36.

EDUSC, 2005.

Um historiador fala de teoria e metodologia: ensaios. Bauru,

CARVALHO, Alexandre Galvão. A "economia antiga" e o nascimento da ciência histórica na Alemanha. In: A economia antiga: História e historiografia. Vitória da Conquista: UESB, 2011, p. 39-71.

A economia antiga, a modernidade e a relação ocidente e oriente: as contribuições de Karl Marx e Max Weber. In: Heródoto. Unifesp, Guarulhos, v. 3, n. 1, Março, 2018. p. 461-483.

COHN, Gabriel. Introdução. In: Weber: Sociologia. São Paulo: Editora Ática, p. 07-34.

COLOGNESI, Luigi Capogrossi. Il 'feudalesimo cittadino' nella interpretazione weberiana delle società antiche. In: Dialogues d'histoire ancienne. Année 2001, volume 27, nº 1, p. 7- 32.

DABDAB-TRABULSI, José Antonio. Ensaio sobre a mobilização política na Grécia Antiga. Belo Horizonte: Editora UFMG, 2001.

FRANCISCO, Gilberto da Silva; MORALES, Fábio. Desvelando o atenocentrismo. Revista de Cultura e Extensão da USP. São Paulo: ${ }^{0}$ 14, p. 67-79, mar. 2016.

FINLEY, Moses. Economia e sociedade na Grécia Antiga. São Paulo: Martins Fontes, 2013.

A Política no Mundo Antigo. Rio de Janeiro: Zahar Editores, 1985.

FRANCISCO, Gilberto da Silva; MORALES, Fábio. Desvelando o atenocentrismo. Revista de Cultura e Extensão da USP. São Paulo: $n^{\circ} 14$, p. 67-79, mar. 2016. 
FREUND, Julien. Sociologia de Max Weber. Rio de Janeiro: Forense Universitária, 2000.

FUSTEL DE COULANGES, N. D. La Cité Antique: étude sur le culte, le droit, les institutions de la Grèce et Rome. Cambridge: Cambridge University Press, 2009. [1864], facsimile.

FONTANA, Josep. História: Análise do passado e projeto social. Bauru: EDUSC, 1998.

GALLEGO, Julián. La pólis griega antigua y el moderno concepto de Estado. In: Mare Nostrum, São Paulo: vol. 09, nº 2, p. 84-92.

GOLDSTONE, Jack A.; HALDON, John F. Ancient states, empires, and exploitation. In: MORRIS, Ian and SCHEIDEL, Walter (Orgs.). The dynamic of ancient empires: State power form Assyria to Byzantium. Oxford: Oxford University Press, 2009, p. 3-7.

GUARINELLO, Norberto Luiz. Uma morfologia da História: as formas da História Antiga. In: Politeia: História e Sociedade. Vitória da Conquista, v. 3, $\mathrm{n}^{\mathrm{o}} 1,2003, \mathrm{p} .41-61$. . História Antiga. São Paulo: Contexto, 2013.

HANSEN, Mogens H. Polis: An introduction to the Ancient Greek Citi-State. Oxford: Oxford University Press, 2006.

HARTOG, François. Le XIXe Siècle et l'histoire: le cas Fustel de Coulanges. Paris: Éditions du Seuil, 2001.

HÉRAN, F. L'institution démotivée: de Fustel de Coulanges à Durkheim et au-delà. In: Revue Française de Sociologie, 1987, 28-1, p. 67-97.

HORDEN, P.; PURCELL, N. (Orgs.). The Corrupting Sea: a study of Mediterranean History. New York: Willey-Blackwell, 2000.

IGGERS, George G. The german conception of History: The national tradition of historical thought from Herder to the present. Middletown: Wesleyan University Press, 1983.

LISSARRAGUE, François. The Athenian image of the foreigner. In: HARRISON, Thomas (Ed.). Greeks and Barbarians. New York: Routledge, 2002, p. 101-124.

LORAUX, Nicole. Elogio do Anacronismo. In: NOVAES, Adauto (org). Tempo e História. São Paulo: Cia. Das Letras, 1992, p. 57-70. 
MAC GAW, Carlos G. García. La ciudad Antigua: aspectos económicos e historiográficos. Stud. hist., H. ${ }^{a}$ antig. 26, 2008, p. 237-269.

MALKIN, I. A Small Greek World. Networks in the Ancient Mediterranean. Oxford University. Press, 2012.

MARX, Karl. Formações Econômicas pré-capitalistas. Rio de Janeiro: Paz e Terra, 1985.

MATHIAS, Peter. Economic History: Living with the neighbours. In: The journal of European economic history. Rome: Luiss Guido Carli, 2006, p. 1-13.

MEIKISINS-WOOD, Ellen. Peasant-citizen and Slave: the foundations of Athenian democracy. New York: Verso, 1988.

MOERBECK, Guilherme. Um conto de duas cidades: Ensaio sobre a mobilização para a guerra na Atenas Clássica e na Paris da Primeira Guerra Mundial. In: Hélade. Vol. 2, nº 3, Dezembro de 2016, p. 86-97.

Entre a religião e a política: Eurípides e a Guerra do Peloponeso. Curitiba: Editora Prismas, 2017.

caminhos possíveis para o Ensino de História Antiga na educação básica: discussões preliminares. In: Aprendizagens históricas: debates e opiniões. BUENO, André; ESTACHESKI, Dulce; CREMA, Everton; NETO, José Maria (Orgs.). União da Vitória/Rio de Janeiro: SobreOntens, 2018, p. 140-150.

MORLEY, Neville. Ancient history: key themes and approaches. New York: Routledge, 2000.

MORRIS, Ian. Mediterraneanization. In: Mediterranean Historical Review, 18:2, 2003, p. 30-55.

NIPPEL, Wilfried. Introductory remarks: Max Weber's "The City" revisited. In: MOLHO, Anthony; RAAFLAUB, Kurt; EMLEM, Julia (Orgs.). City States in Classical Antiquity and Medieval Italy. Michigan: The University of Michigan Press, 1991, p. 19-30.

OBER, J. Political Dissent in democratic Athens: Intellectual critics of popular rule. New Jersey: Princeton University Press, 1998.

PAIARO, Diego. Entre el "gobierno de la muchedumbre" y la "ditadura del proletariado". La historiografía de la democracia ateniense frente al espejo de la revolución. In: LEONI, Moreno; MATÍAS, Álvaro (Ed.). 
Historiografía moderna y mundo antiguo. Córdoba: Tinta Libre, 2018, p. 93134.

PALMEIRA, Miguel Soares. A nova "economia antiga". In: PIRES, Francisco Murari (Org.). Antigos e modernos: diálogos sobre a (escrita da) história. São Paulo: Alameda, 2009, p. 93-108.

PIRES, Eloiza Gurgel. Experiência e linguagem em Walter Benjamin. In: Educ. Pesqui., São Paulo, v. 40, n. 3, p. 813-828, jul./ set. 2014.

POLIGNAC, F. de. Cults, territory, and the origins of the Greek city-state. Translated by Janet Lloyd. Chicago: The University of Chicago Press. 1995.

POLLAK, Michel. Max Weber: elementos para uma biografia sociointelectual (Parte I). In: Mana: Estudos de Antropologia Social. Vol II, $\mathrm{n}^{\circ}$ 1, Abril de 1996, p. 59-95.

Max Weber: elementos para uma biografia sociointelectual (Parte II). In: Mana: Estudos de Antropologia Social. Vol II, nº 2, Abril de 1996, p. 85-113.

RINGER, Fritz. A metodologia de Max Weber: unificação das ciências culturais e sociais. São Paulo: EDUSP, 2004.

VLASSOPOULOS, Kostas. Unthinking the Greek polis: Ancient Greek history beyond eurocentrism. Cambridge: Cambridge University Press, 2007.

SCHEIDEL, Walter; MORRIS, Ian; SALLER, Richard Introduction. In: . (Ed.). The Cambridge History of the

Greco-Roman World. Cambridge: Cambridge University Press, 2008, p. 1-15.

SHANKS, Michael. Classical Archaeology of Greece: experiences of the discipline. London: Routledge, 1996.

SNODGRASS, Anthony. Archaic Greece: the age of experiment. Berkeley: University of California Press, 1981.

WAGNER, Peter. Transformations of democracy: towards a History of political thought and practice inn long-term perspective. In: ARNASON, Johann P.; RAAFLAUB, Kurt, A; WAGNER, Peter. (Ed.) The Greek polis and the invention of democracy: a politico-cultural transformation and its interpretations. Malden: Wiley-Blackwell, 2013, p. 47-67.

WEBER, Max. Economia e Sociedade. Trad. Gabriel Cohn. Brasília: UnB, 1999, Vol I. 
. Economia e Sociedade. Trad. Gabriel Cohn. Brasília: UnB, 1999b,

Vol II.

Economy and Society: an outline of interpretive sociology. Trad. Guenther Roth and Claus Wittich. Berkeley: University of California Press, 1978.

The theory of social and economic organization. New York: The

Free

Press,

London: Collier MacMillan, 1964.

A ética protestante e o espírito do capitalismo. São Paulo: Martin Claret, 2001.

Ciência e Política: duas vocações. São Paulo: Martin Claret, 2002. 